\title{
Desenvolvimento e validação de modelo de previsão para mancha preta dos citros em função de variáveis meteorológicas
}

\author{
Mariana Vilela Lopes Ninin ${ }^{1,2}$; Marcel Bellato Spósito ; Érika Auxiliadora Giacheto Scaloppi ${ }^{4}$, José Carlos Barbosa \\ Modesto Barreto'.
}

${ }^{1}$ Departamento de Fitossanidade, ${ }^{5}$ Departamento de Ciências Exatas, Faculdade de Ciências Agrárias e Veterinárias/Universidade Estadual Paulista, Via de Acesso Prof. Paulo D. Castellane, s/n, 14.884-900, Jaboticabal, SP, Brasil; ${ }^{2}$ Doutoranda em Produção Vegetal; ${ }^{3}$ Departamento de Produção Vegetal, Escola Superior de Agricultura Luiz de Queiroz, Av. Pádua Dias, 11, 13418-900, Piracicaba, SP, Brasil. ${ }^{4}$ APTA/PRDTA Centro Leste, Av. Bandeirantes, 14030-670, Ribeirão Preto, SP.

Autor para correspondência: Mariana Vilela Lopes Ninin (marianavlopes@yahoo.com.br)

Data de chegada: 13/05/2011. Aceito para publicação em: 16/05/2012.

1753

\section{RESUMO}

Ninin, M.V.L.; Spósito, M.B.; Scaloppi, E.A.G.; Barbosa, J.C.; Barreto, M. Desenvolvimento e validação de modelo de previsão para mancha preta dos citros em função de variáveis meteorológicas. Summa Phytopathologica, v.38, n.4, p.288-293, 2012.

A mancha preta dos citros é uma doença causada pelo fungo Guignardia citricarpa que produz lesões em frutos em variedades de laranja doce comerciais, causando a queda precoce dos frutos, diminuindo a produtividade e levando a sua depreciação para o mercado de fruta fresca. O objetivo do trabalho foi desenvolver e validar um modelo de favorabilidade climática da mancha preta dos citros relacionado a ocorrência dos sintomas da doença no Estado de São Paulo. Desenvolveuse um sistema empírico com base em um banco de dados da ocorrência da doença e das condições climáticas, em campo, nos municípios de Barretos/ SP e Gavião Peixoto/SP, durante as Safras 2007/2008 e 2008/2009. A variedade de laranjeira doce utilizada nos experimentos foi a 'Valência' enxertada sobre limoeiro 'Cravo', com 10 anos de idade. Para a incidência da mancha preta foi avaliada a porcentagem de frutos com sintomas na planta e para a severidade, a porcentagem de casca lesionada por fruto.
$\mathrm{Na}$ análise de regressão as variáveis climáticas e os dados de intensidade de doença de Barretos foram selecionados no procedimento 'stepwise'. As melhores equações de regressão foram selecionadas pelo coeficiente de determinação $\left(\mathrm{R}^{2}\right)$ e pela significância da regressão no teste $\mathrm{F}(\mathrm{P} \leq$ $0,05$ e $\mathrm{P} \leq 0,01)$ que resultou na equação $\mathrm{Y}=-502,43+9,61 \mathrm{X}_{10}+4,7 \overline{8}$ $\mathrm{X}_{30}+0,54 \mathrm{X}_{46}-7,9 \mathrm{X}_{50}$ em que $\mathrm{Y}=$ Índice de Favorabilidade, $\mathrm{X}_{10}$ é a temperatura média, $\mathrm{X}_{30}$ é a umidade relativa média, $\mathrm{X}_{46}$ é o molhamento foliar e $X_{50}$ é a temperatura média durante o molhamento foliar, determinados com dados de intervalos de sete dias. Procedeu-se a validação no campo no município de Gavião Peixoto durante a Safra 2008/2009, realizando a correlação entre a incidência e severidade observadas no experimento e os dados previstos que foram os determinados pela equação, sendo que a correlação mostrou-se positiva para a incidência da doença com um $\mathrm{R}^{2}=0,87$.

Palavras-chave adicionais: Citros, Guignardia citricarpa, favorabilidade climática

\section{ABSTRACT}

Ninin, M.V.L.; Spósito, M.B.; Scaloppi, E.A.G.; Barbosa, J.C.; Barreto, M. Development and validation of a forecast model for citrus black spot according to meteorological variables. Summa Phytopathologica, v.38, n.4, p.288-293, 2012.

Citrus black spot is a disease caused by Guignardia citricarpa which produces lesions in fruits of commercial varieties of sweet orange, causing premature fall of fruits, decreasing the yield and leading to depreciation of the fresh fruit market. The aim of this study was to develop and validate a model of climate favorability for citrus black spot related to the occurrence of the disease symptoms in the state of São Paulo (SP). An empirical system was developed based on a data bank of the disease occurrence and the climate conditions in the field in the municipalities of Barretos/SP and Gavião Peixoto/SP, during the 2007/2008 and 2008/2009 crop cycles. The sweet orange variety used in the experiments was 'Valencia' grafted onto 'Rangpur' lime aged 10 years. For black spot incidence, the percentage of fruits with symptoms in the plant was evaluated, and for severity, the percentage of skin lesions per fruit was assessed. In the regression analysis, the climate variables and the data related to the disease intensity in Barretos were selected in the 'stepwise' procedure. The best regression equations were selected by the coefficient of determination $\left(\mathrm{R}^{2}\right)$ and by the significance of regression in the $\mathrm{F}$ test $(\mathrm{P}<0.05$ and $\mathrm{P}<0.01)$, which resulted in the equation $\mathrm{Y}=-502.43+$ $9.61 \mathrm{X}_{10}+4.78 \mathrm{X}_{30}+0.54 \mathrm{X}_{46}-7.9 \mathrm{X}_{50}$, where $\mathrm{Y}=$ Favorability Index, $\mathrm{X}_{10}$ is the average temperature, $\mathrm{X}_{30}$ is the average relative humidity, $\mathrm{X}_{46}$ is the leaf wetness and $\mathrm{X}_{50}$ is the average temperature during leaf wetness, determined with data from 7-day intervals. Validation was carried out in the field in Gavião Peixoto Municipality during the 2008/2009 crop cycle, correlating the incidence and severity observed in the experiment with the predicted data that were determined by the equation, and the correlation was positive for the disease incidence with $\mathrm{R}^{2}=0.87$. 
A mancha preta dos citros (MPC), também denominada pinta preta, é uma doença causada pelo fungo Guignardia citricarpa Kiely [anamorfo: Phyllosticta citricarpa (McAlp.) Van der Aa], responsável por elevados prejuízos na cultura dos citros (5). Do ponto de vista econômico, sua importância reside pelo fato de atingir as variedades mais importantes, depreciar os frutos comercialmente e reduzir a produtividade devido à queda precoce das frutas; do ponto de vista de controle, dada às dificuldades pertinentes; e pelo ponto de vista epidemiológico, dado ao longo período de incubação do fungo, longo período de suscetibilidade dos frutos, existência de condições ambientais favoráveis à formação do inóculo e, ainda, à ocorrência de epidemias severas em pomares de importantes regiões citrícolas do Estado de São Paulo, principal produtor do país $(7 ; 11)$.

A mancha preta dos citros expressa diferentes tipos de sintomas. O primeiro a se expressar em áreas onde a doença já está endêmica é a falsa melanose, quando os frutos ainda se encontram verdes (6). O sintoma típico da doença é conhecido como mancha dura, e se expressa nos frutos a partir da fase de mudança de cor do verde para o amarelo, e caracteriza-se por manifestar lesões inicialmente pardo-avermelhadas e, posteriormente, escuras, deprimidas e com centro acinzentado, contendo picnídios (6).

Um fator importante para a expressão dos sintomas é o período de incubação variável da MPC (1). Os frutos estão sempre suscetíveis, desde a queda das pétalas até a sua maturação plena (3). Quando a infecção ocorre em frutos com diâmetro de aproximadamente $1,5 \mathrm{~cm}$ a expressão dos sintomas ocorre em período superior a 200 dias, enquanto que, frutos próximos a maturação, com mais de $5 \mathrm{~cm}$ de diâmetro, esse período é reduzido para menos de um mês (1).

O período de incubação variável pode estar relacionado à resistência de frutos imaturos à colonização pelo patógeno, baseada em alguns mecanismos, tais como, compostos tóxicos presentes nos frutos imaturos, como fenóis, a presença de substâncias complexas inadequadas para a nutrição do patógeno, quantidade inadequada de enzimas produzidas pelo patógeno para degradar as substâncias pécticas da parede celular do fruto ou a produção de fitoalexinas nos frutos pós infecção (8). O processo de amadurecimento e senescência dos frutos, geralmente, reduz as respostas de resistência (4)

A manifestação dos sintomas é favorecida pela radiação solar combinada com altas temperaturas, portanto, frutos mais expostos ao sol, em geral, expressam mais sintomas (5).

Portanto, a expressão dos sintomas é dependente de dois fatores, a presença de inóculo na área e condições ambientais favoráveis à infecção e o desenvolvimento dos frutos e condições favoráveis para a expressão dos sintomas (8).

Fatores como temperatura e precipitação pluvial, que variam nas regiões citrícolas, influenciam tanto na sobrevivência, na esporulação e na dispersão do patógeno, como na fisiologia do hospedeiro (época de florescimento, taxa de crescimento dos frutos) que somados determinam o início e a duração do período de infecção (2).

O conhecimento dos efeitos da interação entre os fatores ambientais e as diferentes fases do ciclo da doença, assim como do hospedeiro, permite a previsão com maior acerto não somente da ocorrência de epidemias, mas também da taxa de aumento das doenças.

O objetivo do presente trabalho foi desenvolver e validar um modelo de favorabilidade climática da mancha preta dos citros relacionado a ocorrência dos sintomas da doença no Estado de São Paulo.

\section{MATERIAL E MÉTODOS}

Foram realizados dois experimentos de campo nos municípios de Barretos e Gavião Peixoto, Estado de São Paulo, durante as safras 2007/2008 e 2008/2009.

A variedade de laranjeira doce utilizada nos campos experimentais foi 'Valência' enxertada sobre limoeiro 'Cravo', com 10 anos de idade. Durante todo o período de experimentação, ambas as áreas experimentais não receberam tratamento fungicida.

Em cada área experimental foram selecionadas 30 plantas (cinco ruas de seis plantas), onde, para se obter um banco de dados dos sintomas da mancha preta dos citros, foram realizadas avaliações em intervalos de 15 dias desde o surgimento dos primeiros sintomas até a colheita em 50 frutos por planta, quanto a incidência (porcentagem de frutos sintomáticos) e severidade da doença (porcentagem da área da casca dos frutos com sintomas da doença). Para a avaliação da

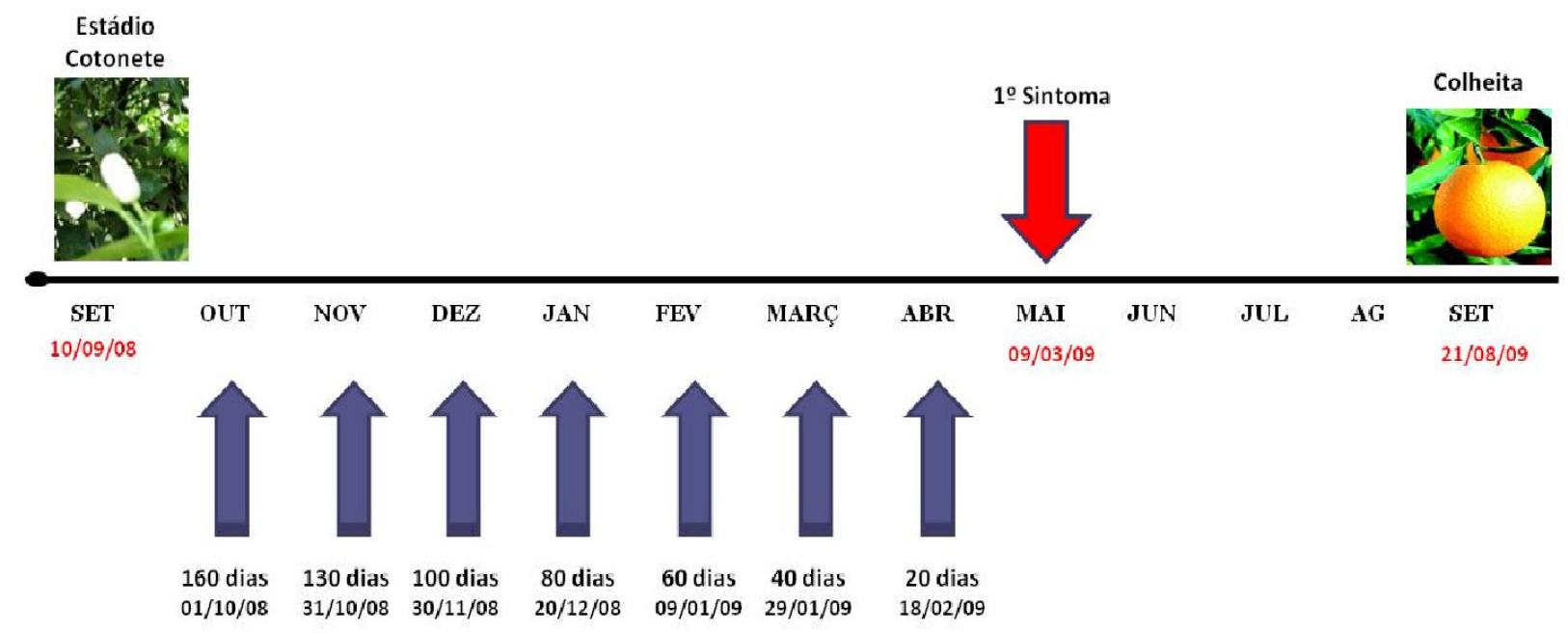

Figura 1. Representação esquemática do início da análise dos dados de 20 a 160 dias antes do aparecimento do primeiro sintoma (das) da mancha preta em frutos de citros durante a Safra 08/09. 
severidade da doença foi utilizada escala diagramática (11).

Foi utilizado um sistema automático de aquisição de dados ambientais, modelo Vantage Pró, da Marca Davis. As plataformas de aquisição de dados forneceram os dados relativos às condições meteorológicas gerais (macroclimáticas), além de conter um conjunto de sensores com um psicrômetro e um sensor de molhamento. As variáveis monitoradas foram medidas a cada minuto e armazenadas na média a cada 30 minutos pela média dos valores ou seu total, no caso de precipitação pluvial.

Com o objetivo de realizar as análises exploratórias dos dados para se verificar possíveis efeitos de todas as variáveis meteorológicas monitoradas na expressão dos sintomas da mancha preta dos citros, foram obtidas equações de regressão múltipla para os dados obtidos nos experimentos conduzidos no município de Barretos.

Para a análise de regressão, as variáveis foram selecionadas no procedimento 'stepwise' pelo programa SAS. Selecionaram-se as variáveis significativas a $5 \%$ de probabilidade pelo teste F. As melhores equações de regressão foram selecionadas pelo coeficiente de determinação $\left(\mathrm{R}^{2}\right)$ e pela significância da regressão no teste $\mathrm{F}(\mathrm{P} \leq 0,05$ e $\mathrm{P} \leq 0,01)$.

Baseando-se nos dados da ocorrência de sintomas de mancha preta dos citros e nas condições climáticas obtidas na lavoura, no período referido, foram realizadas as análises de regressão múltipla entre o aumento da doença (calculado) e os parâmetros climáticos: temperatura do ar (média diária; média diurna, considerada no período das $6 \mathrm{~h}$ as 17:30h e média durante as horas de molhamento foliar), número de horas de molhamento foliar (somatória diária), umidade relativa do ar (média diária e média diurna, considerada no período das 6h as 17:30h) e precipitação pluvial (somatória diária) aos 160, 130, 100, 80, 60, 40 e 20 dias antes do aparecimento do primeiro sintoma da doença (Figura 1). As regressões foram entre o progresso da doença e cada parâmetro climático em conjuntos de 5 em 5, 7 em 7, 10 em 10 e 12 em 12 dias a partir dos intervalos citados anteriormente, totalizando 60 variáveis nomeadas de $\mathrm{X}_{1}$ a $\mathrm{X}_{60}$.

No diagrama da Figura 2 é apresentado o esquema ilustrativo de como as variáveis climáticas foram consideradas em diferentes períodos procedentes. O diagrama mostra o período compreendido entre duas avaliações. A taxa da doença foi considerada a total no período, tendo em vista que esta doença não tem seu progresso de forma linear.

Com a equação gerada foi realizada a validação utilizando-se os dados experimentais do município de Gavião Peixoto e correlacionados para verificar a acurácia da equação.

\section{RESULTADOS E DISCUSSÃO}

As equações de regressão múltipla desenvolvidas para previsão do aparecimento dos sintomas da MPC levaram em consideração o nível de doença no período e diferentes parâmetros climáticos.

Devido ao elevado número de combinações entre as variáveis independentes para estimativas da incidência e severidade, apenas as que mostraram maiores coeficientes de determinação serão apresentadas nos resultados.

Com relação a incidência e severidade da mancha preta dos citros nos municípios de Barretos (Safra 07/08 e Safra 08/09) e Gavião Peixoto (Safra 07/08) as Figuras 3 e 4 apresentam a evolução da doença ao longo das avaliações.

Os maiores coeficientes de determinação, tanto para a incidência quanto para a severidade da MPC, foram obtidos quando utilizou-se a média dos parâmetros climáticos de 7 em 7 dias (Tabelas 01 e 02).

A equação com maior coeficiente de determinação para a incidência da mancha preta dos citros foi a que analisou os parâmetros a partir de 130 dias antes do aparecimento dos primeiros sintomas, correspondendo a 7 dias após a queda de $2 / 3$ das pétalas (final do florescimento), sendo expressa da seguinte forma:

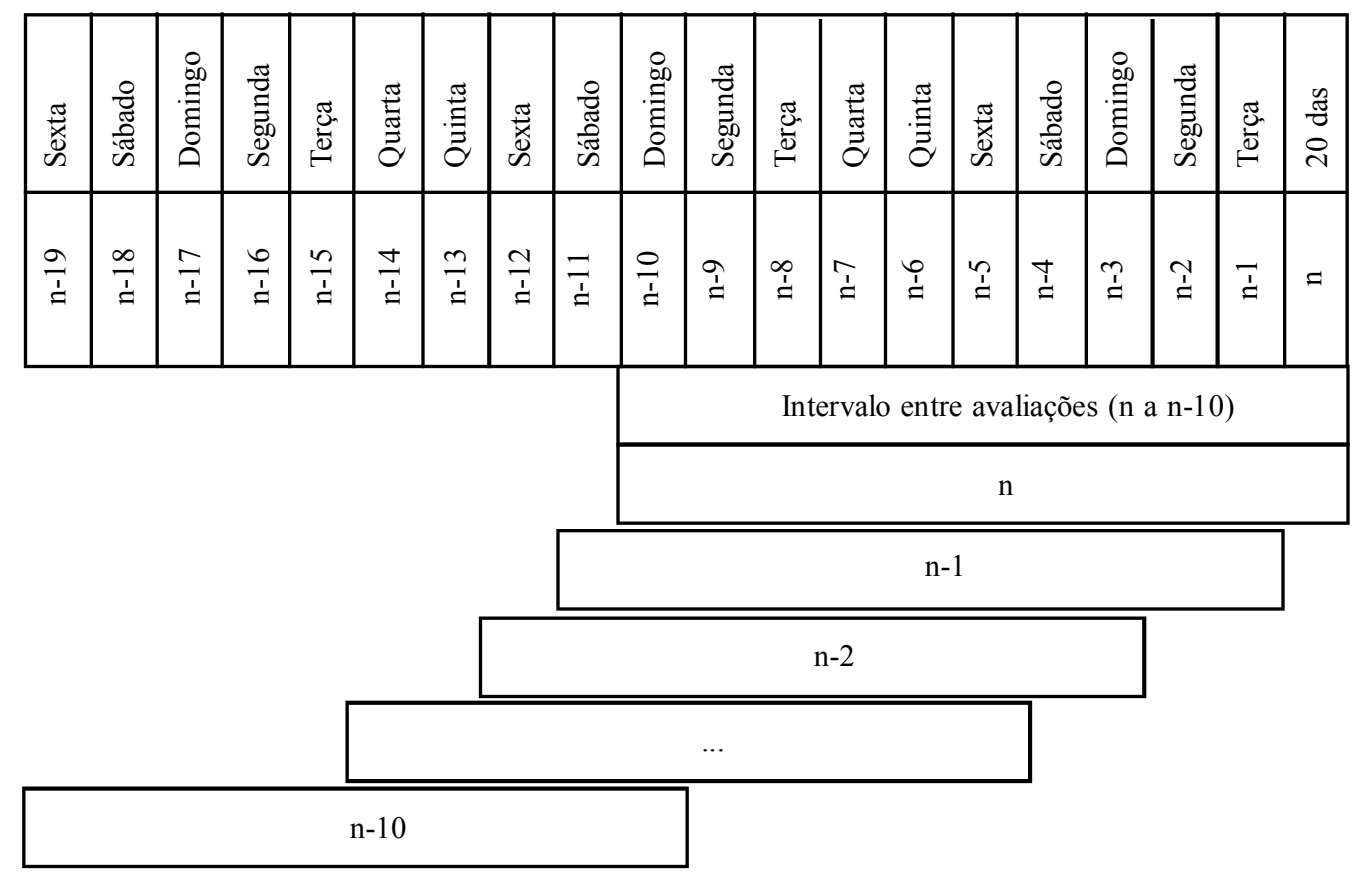

Figura 2 - Representação esquemática de como a taxa da mancha preta em frutos de citros sob intervalo entre duas avaliações foi analisada em relação às variáveis meteorológicas em diferentes períodos, desde 20 dias antes do aparecimento do primeiro sintoma da doença (das). 

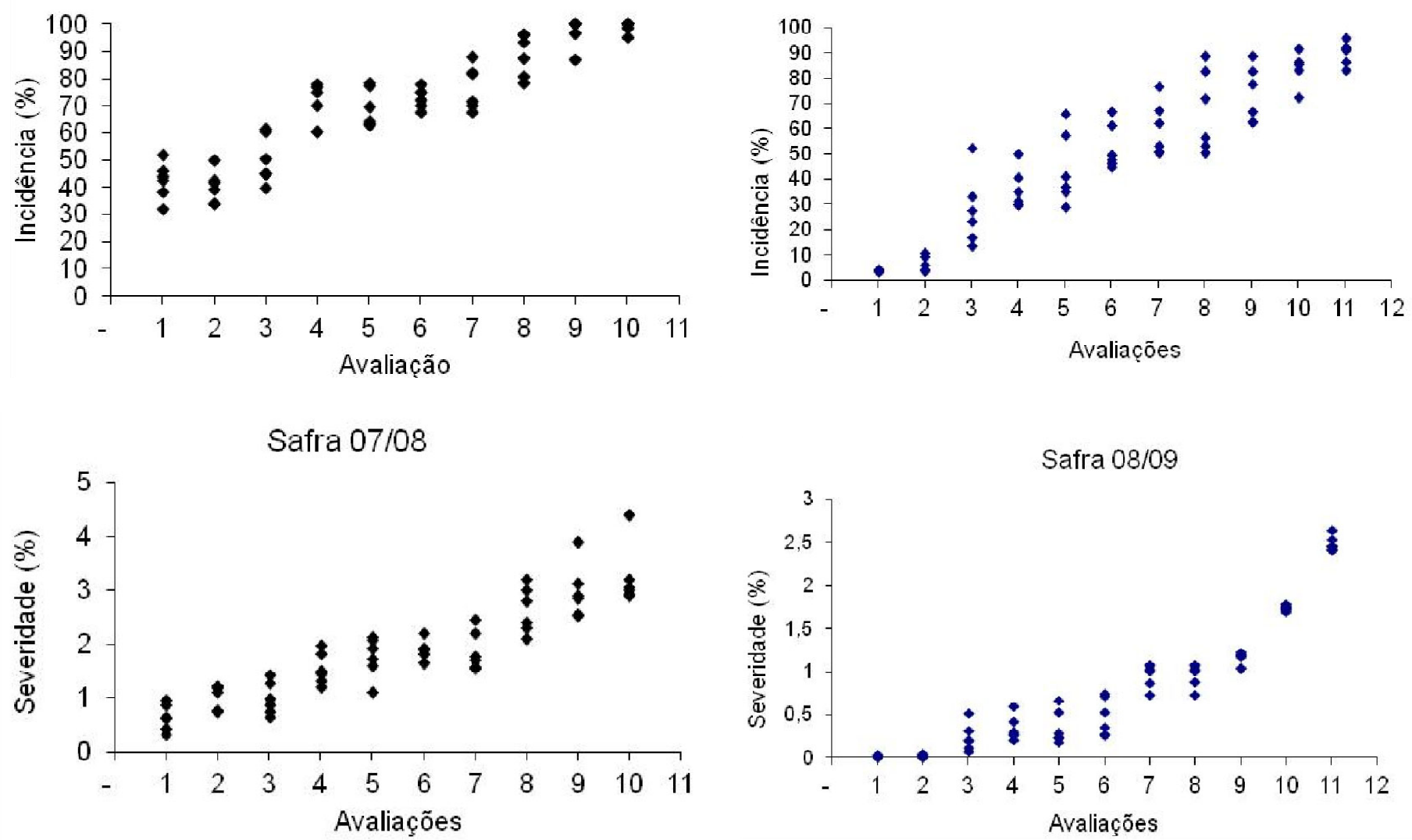

Figura 3. Evolução da mancha preta em frutos de citros no município de Barretos/SP, durante as Safras 07/08 e 08/09
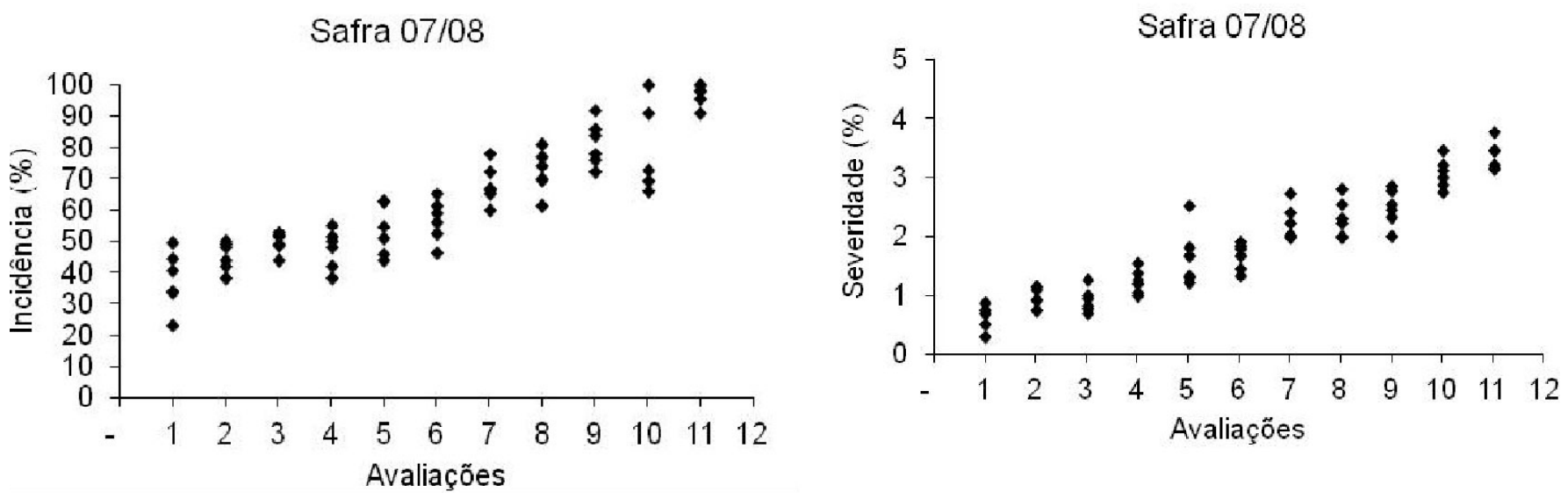

Figura 4. Evolução da mancha preta em frutos de citros no município de Gavião Peixoto/SP, durante a Safra 07/08.

$Y=-502,43+9,61 X_{10}+4,78 X_{30}+0,54 X_{46}-7,9 X_{50}$

Em que:

$\mathrm{X}_{10}$ : Temperatura média analisada a cada 7 dias;

$\mathrm{X}_{30}$ : Umidade relativa analisada a cada 7 dias;

$\mathrm{X}_{46}$ : Molhamento foliar soma analisada a cada 7 dias; e

$\mathrm{X}_{50}$ : Temperatura média durante o molhamento foliar analisada a cada 7 dias.

Para a severidade a equação que apresentou maior coeficiente de determinação foi obtida com dados a partir dos 100 dias antes do aparecimento do primeiro sintoma da doença:

$\mathrm{Y}=15,25-0,32 \mathrm{X}_{10}-0,09 \mathrm{X}_{30}-0,07 \mathrm{X}_{42}+0,007 \mathrm{X}_{46}$

Em que:
$\mathrm{X}_{10}$ : Temperatura média analisada a cada 7 dias;

$\mathrm{X}_{30}$ : Umidade Relativa analisada a cada 7 dias;

$\mathrm{X}_{42}$ : Precipitação analisada a cada 7 dias; e

$\mathrm{X}_{46}$ : Molhamento foliar soma analisada a cada 7 dias.

De posse das equações foi realizada a validação no município de Gavião Peixoto para os dados da Safra 2007/2008 realizando a correlação entre a incidência e severidade observadas no experimento e os dados previstos que foram os determinados pela equação, sendo que a correlação mostrou-se positiva para a incidência com $u m \mathrm{R}^{2}=0,87$ (Figura 05).

Os sintomas da MPC, especialmente os do tipo mancha-dura, 


\begin{tabular}{cccccccccc}
\hline $\begin{array}{c}\text { Dias antes do } \\
\text { aparecimento do } \\
\text { primeiro sintoma }\end{array}$ & Intersecção & $\begin{array}{c}\text { Temperatura } \\
\text { média }\left({ }^{\circ} \mathrm{C}\right)\end{array}$ & $\begin{array}{c}\text { Temperatura } \\
\text { média diurna } \\
\left({ }^{\circ} \mathrm{C}\right)\end{array}$ & $\begin{array}{c}\text { UR } \\
\text { média } \\
(\%)\end{array}$ & Precipitação & $\begin{array}{c}\text { Olhamento } \\
\text { foliar (MF) }\end{array}$ & $\begin{array}{c}\text { Temp. média } \\
\text { durante MF }\end{array}$ & $\mathrm{R}$ & $\mathrm{F}$ \\
\hline 20 & 171,36 & 0,00 & 0,00 & $-1,51$ & 0,00 & $-0,58$ & 4,44 & 0,82 & 26,37 \\
40 & 82,06 & 8,79 & $-13,49$ & 0,00 & 0,00 & 0,00 & 0,00 & 0,76 & 29,93 \\
60 & 180,08 & 0,00 & $-7,35$ & 0,00 & 0,00 & 0,00 & 0,00 & 0,79 & 73,69 \\
80 & 226,76 & $-6,88$ & 0,00 & 0,00 & 0,00 & 0,24 & $-3,27$ & 0,72 & 14,94 \\
100 & 428,56 & 0,00 & $-4,86$ & $-3,68$ & $-4,48$ & 0,36 & 0,00 & 0,89 & 13,34 \\
130 & $-502,43$ & 9,61 & 0,00 & 4,78 & 0,00 & 0,54 & $-7,90$ & 0,94 & 25,54 \\
160 & $-647,10$ & 0,00 & 13,15 & 4,53 & 0,00 & 0,00 & 0,00 & 0,82 & 19,36 \\
\hline
\end{tabular}

Tabela 1. Relação entre a incidência dos sintomas da mancha preta em frutos de citros e as variáveis climáticas. Barretos/SP.

\begin{tabular}{cccccccccc}
\hline $\begin{array}{c}\text { Dias antes do } \\
\text { aparecimento do } \\
\text { primeiro sintoma }\end{array}$ & Intersecção & $\begin{array}{c}\text { Temperatura } \\
\text { média }\left({ }^{\circ} \mathrm{C}\right)\end{array}$ & $\begin{array}{c}\text { Temperatura } \\
\text { média diurna } \\
\left({ }^{\circ} \mathrm{C}\right)\end{array}$ & $\begin{array}{c}\text { UR } \\
\text { média } \\
(\%)\end{array}$ & Precipitação & $\begin{array}{c}\text { Olhamento } \\
\text { foliar (MF) }\end{array}$ & $\begin{array}{c}\text { Temp. média } \\
\text { durante MF }\end{array}$ & $\mathrm{R}$ & $\mathrm{F}$ \\
\hline 20 & 7,44 & 0,00 & 0,00 & $-0,09$ & 0,00 & $-0,01$ & 0,13 & 0,87 & 41,06 \\
40 & 8,87 & 0,00 & 0,00 & $-0,10$ & 0,00 & 0,00 & 0,00 & 0,74 & 55,93 \\
60 & 9,11 & 0,00 & $-0,14$ & $-0,07$ & 0,00 & 0,00 & 0,00 & 0,74 & 26,55 \\
80 & 11,75 & $-0,28$ & 0,00 & $-0,05$ & 0,00 & 0,00 & 0,00 & 0,69 & 20,32 \\
100 & 15,25 & $-0,32$ & 0,00 & $-0,09$ & $-0,07$ & 0,01 & 0,00 & 0,95 & 32,76 \\
130 & $-3,80$ & 0,00 & 0,00 & 0,07 & 0,00 & 0,01 & $-0,22$ & 0,92 & 30,53 \\
160 & $-4,88$ & 0,00 & 0,00 & 0,09 & 0,00 & 0,03 & $-0,28$ & 0,84 & 12,52 \\
\hline
\end{tabular}

Tabela 2. Relação entre a severidade dos sintomas da mancha preta em frutos de citros e as variáveis climáticas. Barretos/SP.

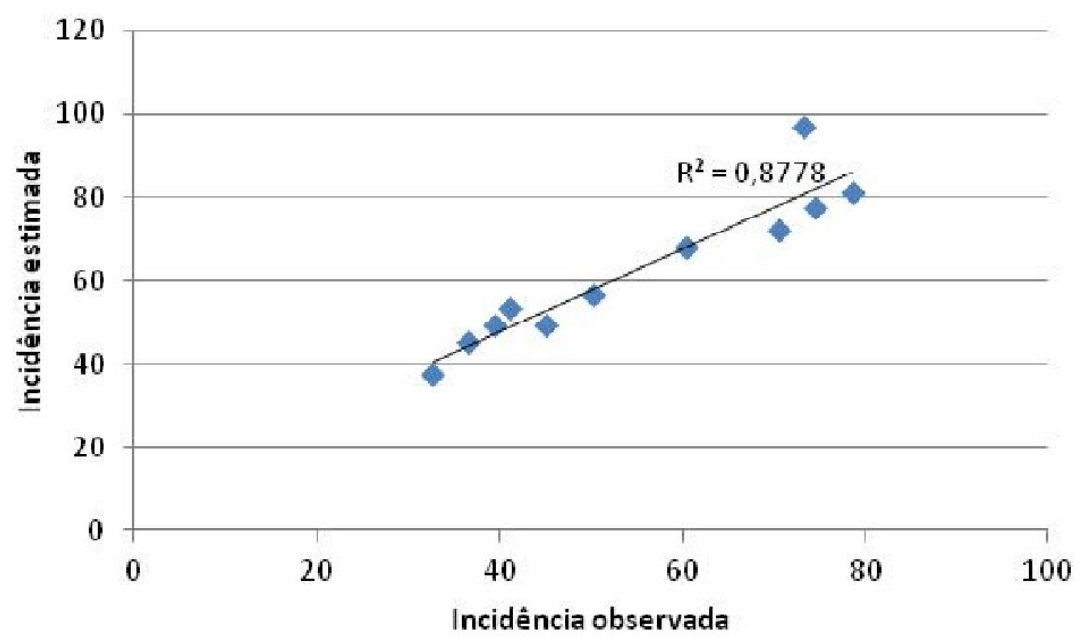

Figura 5. Regressão entre a incidência estimada e observada para mancha preta em frutos de citros no município de Gavião Peixoto/SP durante a Safra 07/08.

normalmente se mostram mais evidentes a partir das fases iniciais de maturação dos frutos (10). A magnitude da expressão dos sintomas, contudo, mostra-se relacionada com as fases subseqüentes de desenvolvimento e maturação dos frutos. Entretanto, no Brasil, os sintomas de MPC tornam-se mais expressivos nos meses mais quentes da primavera e do verão, sendo dessa forma mais pronunciados nas variedades de maturação tardia (5).

Nas equações obtidas tanto para incidência como para severidade, pode-se observar que a temperatura média foi um dos fatores climáticos que influenciaram na expressão dos sintomas da mancha preta dos citros, além de outros como o molhamento foliar e umidade média relativa.

Dessa forma, torna-se evidente que, mais que propriamente a fase de maturação dos frutos, o ambiente tem impacto muito mais relevante, dado os efeitos mais significativos da radiação solar, como demonstrado por Krajewisk e Rabie (9). Além disso, a maior severidade de sintomas 
da doença normalmente está associada à elevação de temperatura por ocasião da maturação dos frutos, maior estresse hídrico e debilidade das plantas (10).

\section{REFERÊNCIAS BIBLIOGRÁFICAS}

1. Aguiar, R.L. Período de incubação de Guignardia citricarpa em frutos de laranja "Valência" e importância das pulverizações de cobre no controle da mancha preta. 2011. 49f. Tese (Doutorado em Agronomia - Produção Vegetal) - Faculdade de Ciências Agrárias e Veterinárias, Universidade Estadual Paulista, Jaboticabal, 2011.

2. Alcoba, N.J.; Vigiani, A.R.; Bejarano, N.V.; Alavarez, S.E.; Serrano, M.A.; Bonillo, M.C. Mancha negra de los cítricos: epidemiologia y control. San Salvador de Jujuy: Ediciones Universidad Nacional de Jujuy. 2000. 56p.

3. Almeida, T.F. Mancha preta dos citros: expressão dos sintomas em frutos pela inoculação com conídios e controle do agente causal (Guignardia citricarpa). 2009. 66f. Tese (Doutorado em Agronomia - Produção Vegetal) - Faculdade de Ciências Agrárias e Veterinárias, Universidade Estadual Paulista, Jaboticabal, 2009.

4. Benato, E.A. Indução de resistência no controle de doenças pós colheita: frutas e hortaliças. In: Reunião Brasileira sobre Indução de Resistência em plantas contra fitopatógenos, 1. 2002, São Pedro. Resumos... São Pedro: 2002. p.29-31.

5. Feichtenberger, E.; Bassanezi, R.B.; Spósito, M.B.; Belasque, Jr.. Doenças do citros. In: KIMATI, H., AMORIM, L.; REZENDE, J.A.M.; BERGAMIM FILHO, A.; CAMARGO, L.E.A. (Ed.). Manual de fitopatologia: doenças das plantas cultivadas. 4 ed. São Paulo: Agronômica Ceres, 2005. v.2, p.239-269.

6. Fundecitrus. Manual técnico sobre pinta preta. Araraquara: Fundo Paulista de Defesa da Citricultura, 1998. 10p. (Boletim Técnico).

7. Goes, A.; Baldassari, R.B.; Feichtenberger, E.; Aguilar-Vildoso, C.I.; Spósito, M.B. Craked spot, a new symptom of citrus black spot in Brazil. Proceedings of the International Society of Citriculture, Orlando, p.1001-1002, 2000.

8. Jeffries, P.; Dodd, J.C.; Jeger, M.J.; Plumbey, R.A. The biology and control of Colletotrichum species on tropical fruits crop. Plant Pathology, Oxford, v.39, p.346-366, 1990.

9. Krajewisk, A.J.; Rabie, E. Citrus flowering: a critical evaluation. Journal of Horticultural Science, London, v.70, n.3, p.357$374,1995$.

10. Kotzé, J.M. Epidemiology and control of citrus black spot in South África. Plant Disease, v.65, n.12, p.945-950, 1981.

11. Spósito, M. B.; Amorim, L.; Belasque Jr., J.; Bassanezi, R. B.; Aquino, R. de. Elaboração e validação de escala diagramática para avaliação da severidade da Mancha Preta em frutos cítricos. Fitopatologia Brasileira, Brasília, v.29, n.1, p.81-85, 2004. 